\title{
Evolution of microstructure and mechanical properties of $\mathrm{A} 356$ aluminium alloy processed by hot spinning process
}

\author{
*Xiao-yan Wu, Hua-rui Zhang, Huan-liang Chen, Li-na Jia, and Hu Zhang \\ School of Materials Science and Engineering, Beihang University, Beijing 100191, China \\ Beijing Key Laboratory for Advanced Functional Material and Thin Film Technology, Beihang University, Beijing 100191, China
}

\begin{abstract}
The evolution of microstructure and mechanical properties of A356 aluminum alloy subjected to hot spinning process has been investigated. The results indicated that the deformation process homogenized microstructure and improved mechanical properties of the A356 aluminum alloy. During the hot spinning process, eutectic Si particles and Fe-rich phases were fragmented, and porosities were eliminated. In addition, recrystallization of Al matrix and precipitation of AISiTi phases occurred. The mechanical property testing results indicated that there was a significant increase of ductility and a decrease of average microhardness in deformed alloy over die-cast alloy. This is attributed to uniform distribution of finer spherical eutectic Si particles, the elimination of casting defects and to the recrystallized finer grain structure.
\end{abstract}

Key words: hot spinning process; A356 aluminum alloy; microstructure; mechanical properties
CLC numbers: TG146.21
Document code: A
Article ID: 1672-6421(2017)02-138-07

$\mathrm{T}$ he increasing demand for weight reduction in the automotive industry has resulted in a large research interest in aluminum alloys currently. A356 aluminum alloy is a kind of desired and commonly used material in the automotive field, such as suspension components and automotive wheels ${ }^{[1-7]}$. However, A356 products manufactured by casting process generally consist of primary dendrite with non-uniform solute distribution and defects, such as Fe-rich phases and porosities, which may lead to the reduction of service life ${ }^{[8]}$.

Plastic deformation process is definitely an alternative to ameliorate some of the above negative aspects of cast alloys ${ }^{[9,10]}$. Casting-spinning technique is a kind of incremental forming technique employed on circular or tubular cast workpieces ${ }^{[11]}$. During the spinning process, a large amount of plastic deformation occurred. In recent years, the casting-spinning technique has been used in manufacturing automobile hubs. It has been validated that the application of this process is powerful to fulfill

\section{*Xiao-yan Wu}

Female, born in 1989, Ph.D candidate. Her research is focused on high strength and toughness of aluminum alloys.

E-mail:wuxiaoyan@buaa.edu.cn

Corresponding author: huarui@buaa.edu.cn; zhanghu@buaa.edu.cn

Received: 2016-10-09; Accepted: 2017-01-03 the purpose of weight reduction and improvement of properties ${ }^{[12-16]}$.

The influence of hot spinning process on aluminum alloys has been studied by many researchers. Mori et al. ${ }^{[14]}$ researched the effect of spinning parameters on the deformational behavior of automotive hubs. The results indicated that a lower feed rate, a higher tip radius and spinning at $400{ }^{\circ} \mathrm{C}$ were better conditions to eliminate casting defects and reduce the surface cracks. Cheng et al. ${ }^{[12,13]}$ reported that the deformation process improved not only mechanical properties, but also corrosion resistance and anti-wear properties. Zhao et al. ${ }^{[16]}$ found that the peak tensile strength and elongation of A356 alloy were obtained when the reduction in wall thickness is $60 \%$. Roy et al. ${ }^{[15]}$ found that the lower microhardness after deformation was related to the eutectic Si particles size and potential recrystallization.

Although some efforts have been made toward discussing the impact of the spinning process on properties and microstructure in an A356 alloy, the details of evolution of microstructure, the strengthening mechanisms of spinning deformed alloy and the relationship between these parameters were insufficient. Investigations on the relationship between microstructure and mechanical properties will not only form a basis for optimizing properties, but also control and minimize defects. 
Therefore, in this work, the evolution of microstructure and mechanical properties of T6-A356 alloy from die-cast state to deformed state were investigated in detail. The evolution mechanism of microstructure and strengthening mechanism were also analyzed.

\section{Experimental procedures}

\section{1 Specimen preparation}

In this study, the A356 aluminum alloy was received in the form of low pressure die-cast (LPDC) hub and the samples were cut from the billet. They were supplied by SMX Dicastal Wheel Manufacture Company and the chemical composition analyzed by QSN 750-II was shown in Table 1.

Table 1: Actual chemical composition of A356 alloy (wt.\%)

\begin{tabular}{ccccccccc} 
Si & $\mathrm{Mg}$ & $\mathrm{Ti}$ & $\mathrm{Sr}$ & $\mathrm{Fe}$ & $\mathrm{Mn}$ & $\mathrm{Zn}$ & $\mathrm{Cu}$ & $\mathrm{Al}$ \\
\hline 6.98 & 0.3 & 0.12 & 0.0159 & 0.113 & 0.003 & 0.019 & 0.005 & Bal.
\end{tabular}

\section{2 Hot spinning forming experiment}

The hot spinning forming experiment on the as-received A356 aluminum hub was conducted at an elevated temperature. The hot spinning apparatus, including mandrel, roller and the wheel blank are illustrated in Fig. 1 and the experimental parameters are listed in Table 2. After the wheel blank was placed in the mandrel, the mandrel speed was increased to $500 \mathrm{r} \cdot \mathrm{min}^{-1}$, and then the roller was brought into contact in the sequence A-B-C (with the tip radius of $18 \mathrm{~mm}, 12 \mathrm{~mm}$ and $6 \mathrm{~mm}$ respectively) with the blank at a speed of $75 \mathrm{~mm} \cdot \mathrm{min}^{-1}$. The workpiece with high deformation

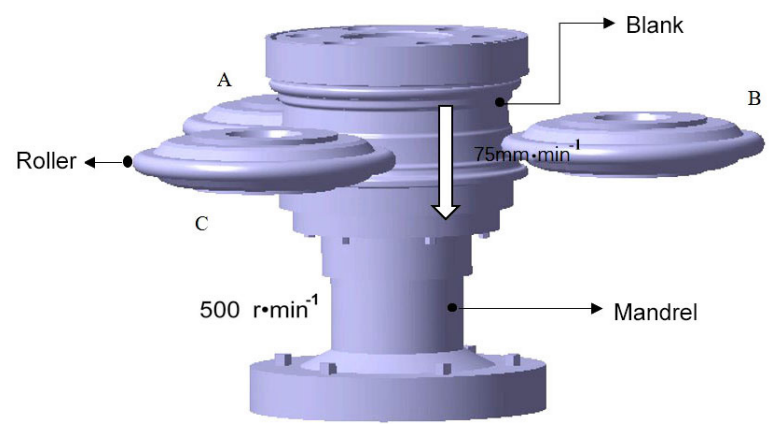

Fig. 1: Experimental rotary forming apparatus
Table 2: Conditions of hot spinning process

\begin{tabular}{lc}
\multicolumn{1}{c}{ Apparatus } & Values \\
\hline Forming temperature $\left({ }^{\circ} \mathrm{C}\right)$ & 385 \\
Feed rate of roller $\left(\mathrm{mm} \cdot \mathrm{min}^{-1}\right)$ & 75 \\
$\begin{array}{c}\text { Tip radius of roller }(\mathrm{mm}) \\
\begin{array}{c}\text { Number of revolutions of mandrel } \\
\left(\mathrm{r} \cdot \mathrm{min}^{-1}\right)\end{array}\end{array}$ & $18 / 12 / 6$ \\
\end{tabular}

(about 60\% deformation recorded as ' $\mathrm{H}$ ') corresponded to normal operation with three rollers; and the low deformation (about $25 \%$ deformation recorded as ' $L$ ') was obtained by operation with only one roller. After the hot spinning process, the blank was removed from the mandrel and subjected to water quenching. For the sake of comparison, die-cast A356 alloy (recorded as "U") was also examined.

\section{3 heat treatment}

All these three kinds of workpieces were subjected to T6 heat treatment, which comprised of solution heat treatment at 540 ${ }^{\circ} \mathrm{C}$ for $5 \mathrm{~h}$, followed by quenching in warm water at $80^{\circ} \mathrm{C}$, and artificially aged at $150{ }^{\circ} \mathrm{C}$ for $2.5 \mathrm{~h}$. The thermal history of hot spinning process was given in Fig. 2.

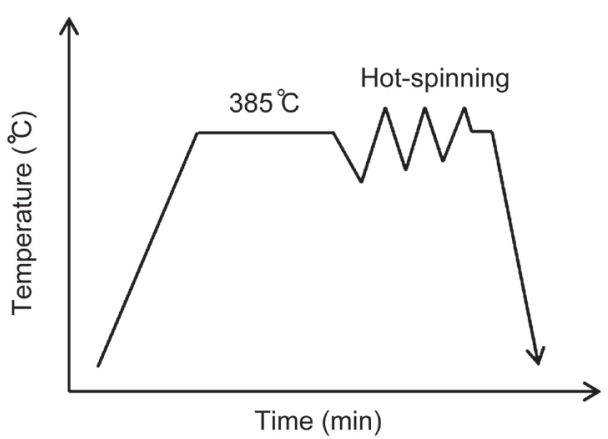

Fig. 2: Schematic diagram of hot spinning test

\section{4 Microstructure analysis}

Various cross-sections were taken from deformed blanks as presented in Fig. 3. These sections were polished to a fine finish and etched in keller and aqua regia, respectively, for examining the corresponding microstructures. In order to reveal the micrograph of eutectic Si particles, the polished specimens were deep etched through immersion in keller's etch for half an hour.

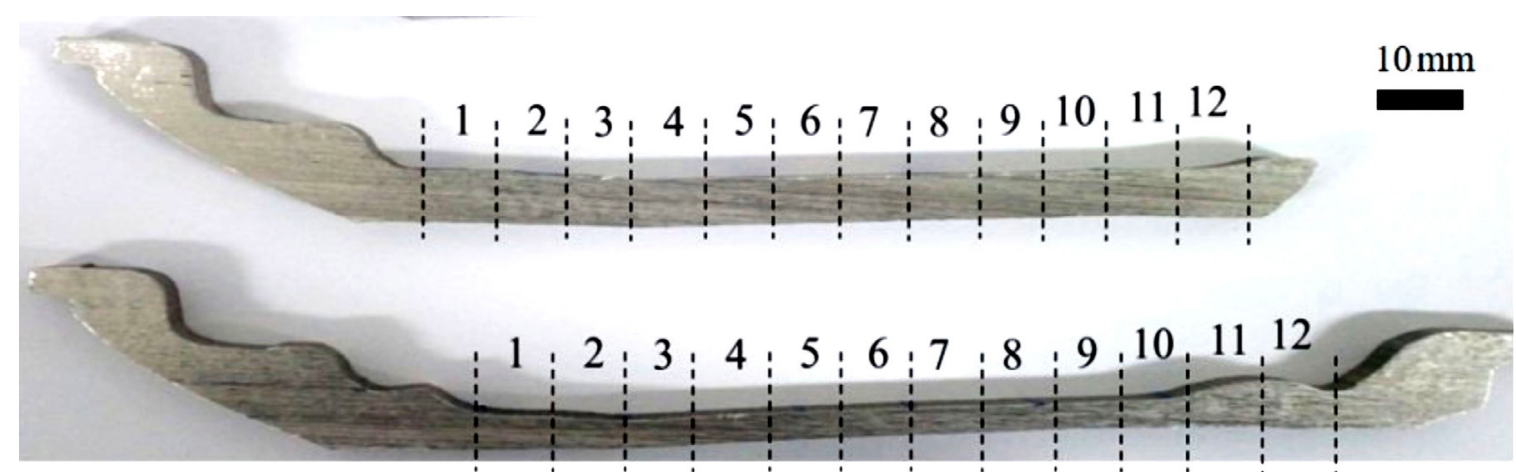

Fig. 3: Various sections taken from deformed banks 
Scanning electron microscope (Camscan-3400) and Optical microscope (LEICA DM4000) were used to measure microstructure and grain structure. Quantitative metallographic analysis was carried out by using image-pro plus analysis software. It was used to measure ${ }^{[17]}$ area, roundness and Feret's dimension of eutectic silicon particles. The dislocation density and composition of the dispersoids were measured through a JEM2100 transmission electron microscope (TEM) equipped with energy dispersive spectroscope (EDS).

\section{5 Mechanical properties tests}

Micro-hardness tests with 100 gf were employed using a FM800 hardness test machine and seven fields were selected to test at random along each of 12 regions in Fig. 3. Tensile samples with the dimension of $6 \mathrm{~mm}$ diameter and $30 \mathrm{~mm}$ gauge length were machined from the die-cast and deformed alloys. Tensile testing was carried out on an Instron 8801 with a cross-head speed of 1 $\mathrm{mm} \cdot \mathrm{min}^{-1}$. From the tensile test data, the quality index, $\mathrm{Q}_{\text {index }}$, was also calculated using the following expression ${ }^{[13,18]}$.

$$
\mathrm{Q}_{\text {index }}=\mathrm{UST}(\mathrm{MPa})+150 \log (\% \mathrm{E})
$$

\section{Experimental results}

\section{1 Microstructure}

\section{1.1 Microstructure of die-cast alloy}

The microstructures of die-cast A356 alloy are presented in Fig. 4. In Fig. 4(a), die-cast A356 alloy consisted of primary $\alpha$-Al matrix and inter-dendritic eutectic regions. Also, casting porosities were present. Fe-rich phases with long rod-like $(\sim 30 \mu \mathrm{m})$ shape are distributed in the eutectic regions as shown in Fig. 4(b). The microstructure of eutectic Si particles demonstrated a fibrous structure with average cross-sectional dimensions of $\sim 1 \mu \mathrm{m}$ width and $\sim 3 \mu \mathrm{m}$ average lengths.
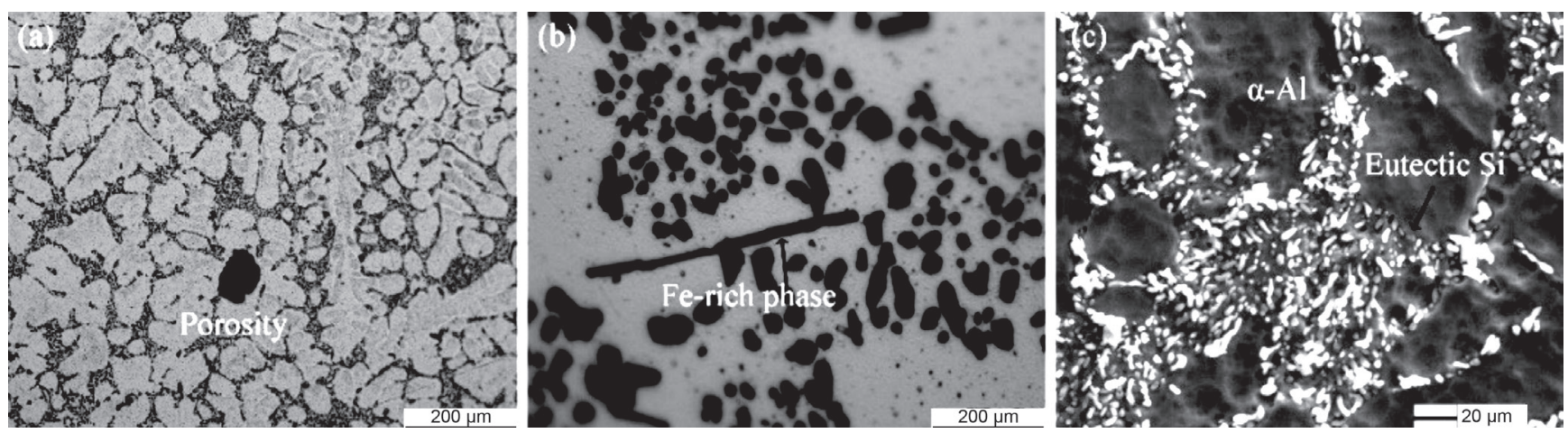

Fig. 4: Microstructure of A356 alloy in die-cast condition: (a) general microstructure taken by OM; (b) magnification image of eutectic and Fe-rich phase; (c) close view taken at eutectic acquired by SEM

\subsubsection{Microstructure of deformed alloy}

Figure 5 shows the overall microstructure performed on axial profiles across the vertical cross-sections of the workpieces for different deformed samples. Owing to the plastic flow of the matrix along the spinning direction, the primary dendrites changed into a microstructure of bands. Axially, the deformation distribution in the specimens was found to be homogenous in regions 4 to 12 . However, due to high deformation [Fig. 5(b)], the distributions of primary $\alpha$-Al phases and $\mathrm{Si}$ particles were inhomogeneous. The 6th regions in both deformed samples were analyzed in detail to illustrate the microstructure evolution caused by deformation.

Figure 6 illustrates the microstructures of samples with different deformations. Significant transformation occurred during the hot spinning process, including the morphologies of porosities, Ferich phases and eutectic Si phases. The microstructure of deformed samples was denser and porosities were eliminated compared with the die-cast sample (Fig. 6a and d). The Fe-rich phases appeared in the Si particle region or the inter-dendrite arms were broken from long-strip structure ( $>20 \mu \mathrm{m})$ (Fig. $4 \mathrm{~b}$ ) to short rod-like structure $(<5 \mu \mathrm{m})$ (Fig. $6 \mathrm{~b}$ and e). It was apparent in Fig. $6 \mathrm{c}$ and $\mathrm{f}$ that $\mathrm{Si}$ particles were significantly fragmented and spheroidized through hot spinning.

Quantitative metallography assessment of the microstructural features of the eutectic Si particles for die-cast and deformed alloys is presented in Table 3. The results showed that the area, roundness and Feret of Si particles all decreased with increasing deformation. Compared with the die-cast alloy, the average dimension values of eutectic Si particles decreased about $38 \%, 19 \%$ and $23 \%$, respectively, in the highly deformed alloy.

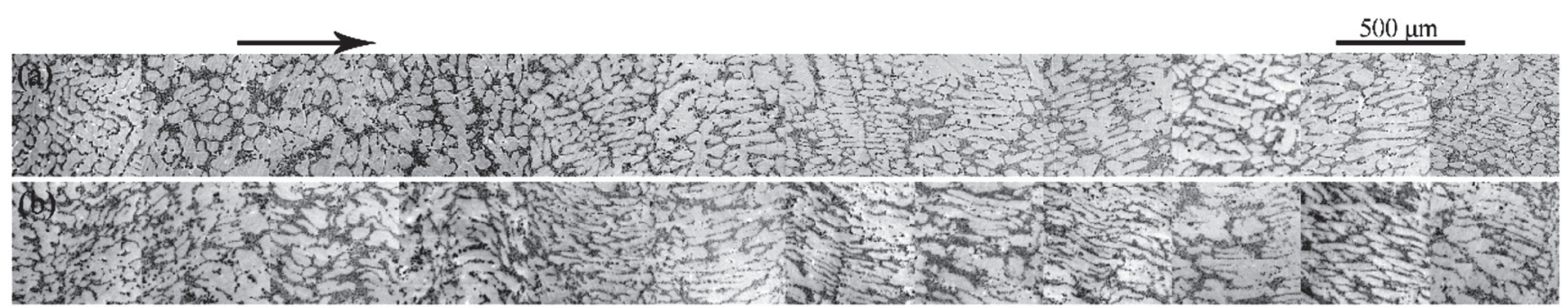

Fig. 5: Microstructure profiles of deformed sections along spinning direction: (a) $L$ and (b) $H$ deformation 

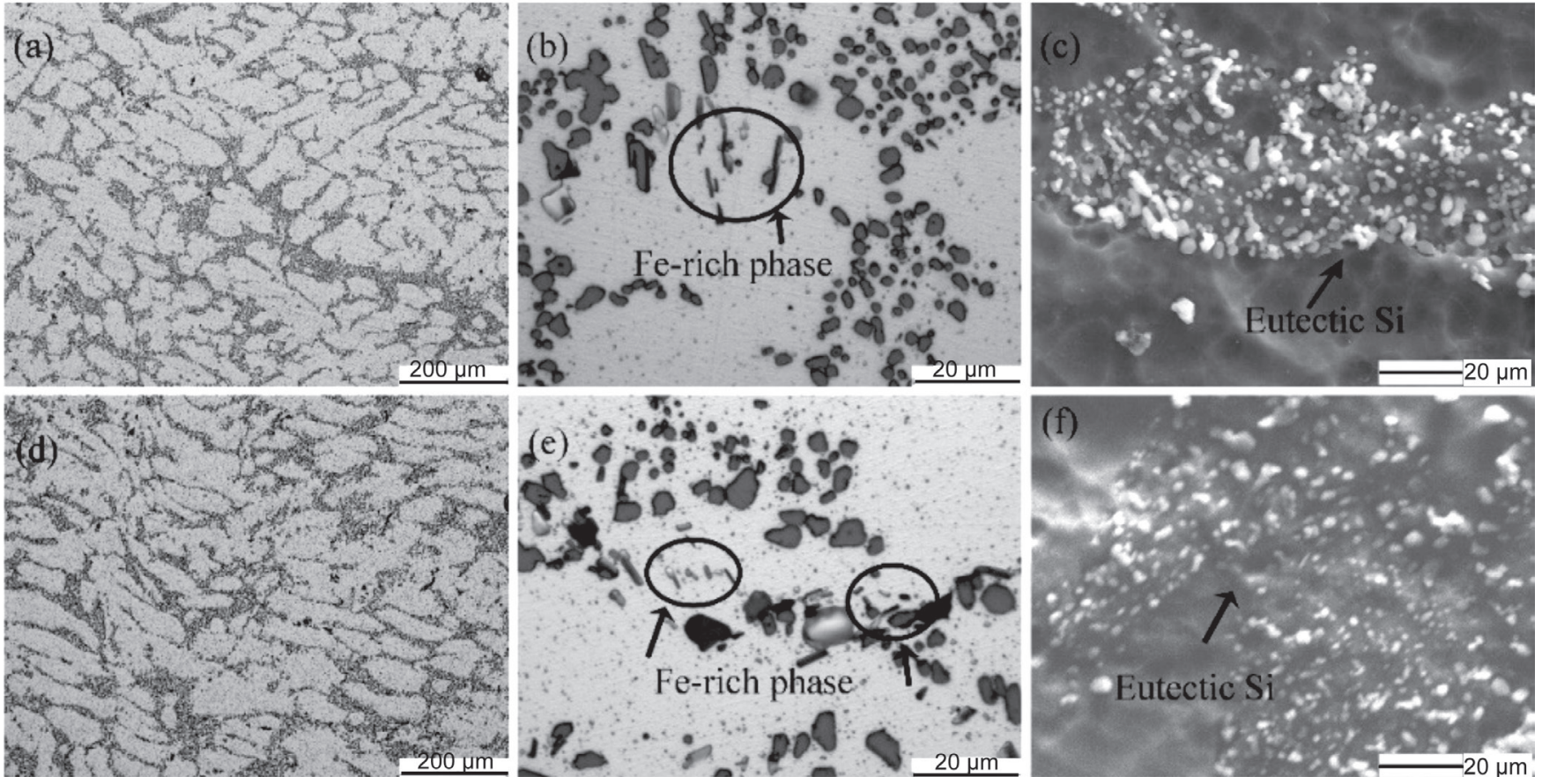

Fig. 6: Typical microstructures of deformed A356 alloy: (a-c) L and (d-f) H deformation. (a) (d) general microstructure taken by OM; (b) (e) magnification images of eutectic Si and Fe-rich phases; (c) (f) close view taken at eutectic acquired by SEM

Table 3: Quantitative analysis results for eutectic Si particles

\begin{tabular}{cccc} 
Alloy & Area $\left(\mu \mathrm{m}^{2}\right)$ & Roundness & Feret $(\mu \mathrm{m})$ \\
\hline U & $5.5 \pm 3.4$ & $1.6 \pm 0.12$ & $2.79 \pm 0.79$ \\
$\mathrm{~L}$ & $4.8 \pm 3.7$ & $1.4 \pm 0.11$ & $2.67 \pm 0.9$ \\
H & $3.4 \pm 1.5$ & $1.3 \pm 0.12$ & $2.16 \pm 0.5$ \\
\hline
\end{tabular}

\subsubsection{Grain structure}

The grain structure is presented in Fig. 7. It can be seen that the grains of deformed alloys were lengthened and refined compared with the die-cast alloy. The grain size of the die-cast alloy was about 300-500 $\mu \mathrm{m}$. However, in the deformed alloys, it was less than $100 \mu \mathrm{m}$ which indicated that recrystallization of the $\mathrm{Al}$ matrix had occurred. Because of the un-matured recrystallization of alloys, the size of grains in Fig. 7 (b) and (c) were not uniform.

\subsection{Dislocations and precipitates}

Figure 8 shows the typical distribution of precipitates and dislocations in the die-cast and deformed samples, respectively. The dislocation density [Fig. 8(a)] in die-cast alloy was rather low and dislocation pinning was hardly observed. On the contrast, the dislocation density was obviously much higher in the deformed alloy. These high density dislocation lines tangled each other, and the dislocations also tangled around the secondary precipitate phases, which produced a strengthening effect through dislocation pinning.

The precipitation phase of $\mathrm{Mg}_{2} \mathrm{Si}$ appeared in die-cast alloy, which had the effect of pinning dislocations during deformation. Due to the dissolution of particles in the Al matrix during the heating process before deformation, the short-rod like $\mathrm{Mg}_{2} \mathrm{Si}$ was relatively less in the deformed alloy ${ }^{[19]}$. However, irregularly shaped particles precipitated from $\alpha$-Al [Fig. 8(d)]. The corresponding EDS analysis is presented in Fig. 8(e). The dispersoid mainly consisted of $\mathrm{Al}, \mathrm{Ti}$, and $\mathrm{Si}$, suggesting that it was a kind of ternary AlTiSi phase. This kind of precipitate was proved to be dynamically precipitated during the deformation process ${ }^{[20]}$.
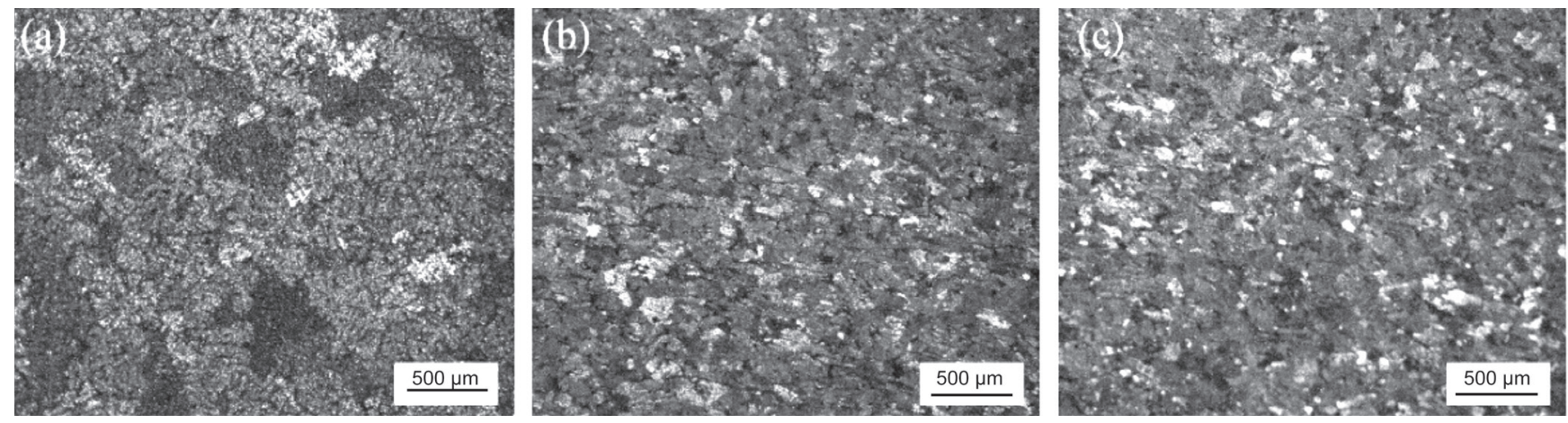

Fig. 7: Grain structure of A356 alloy: (a) U (b) L (c) H deformation 

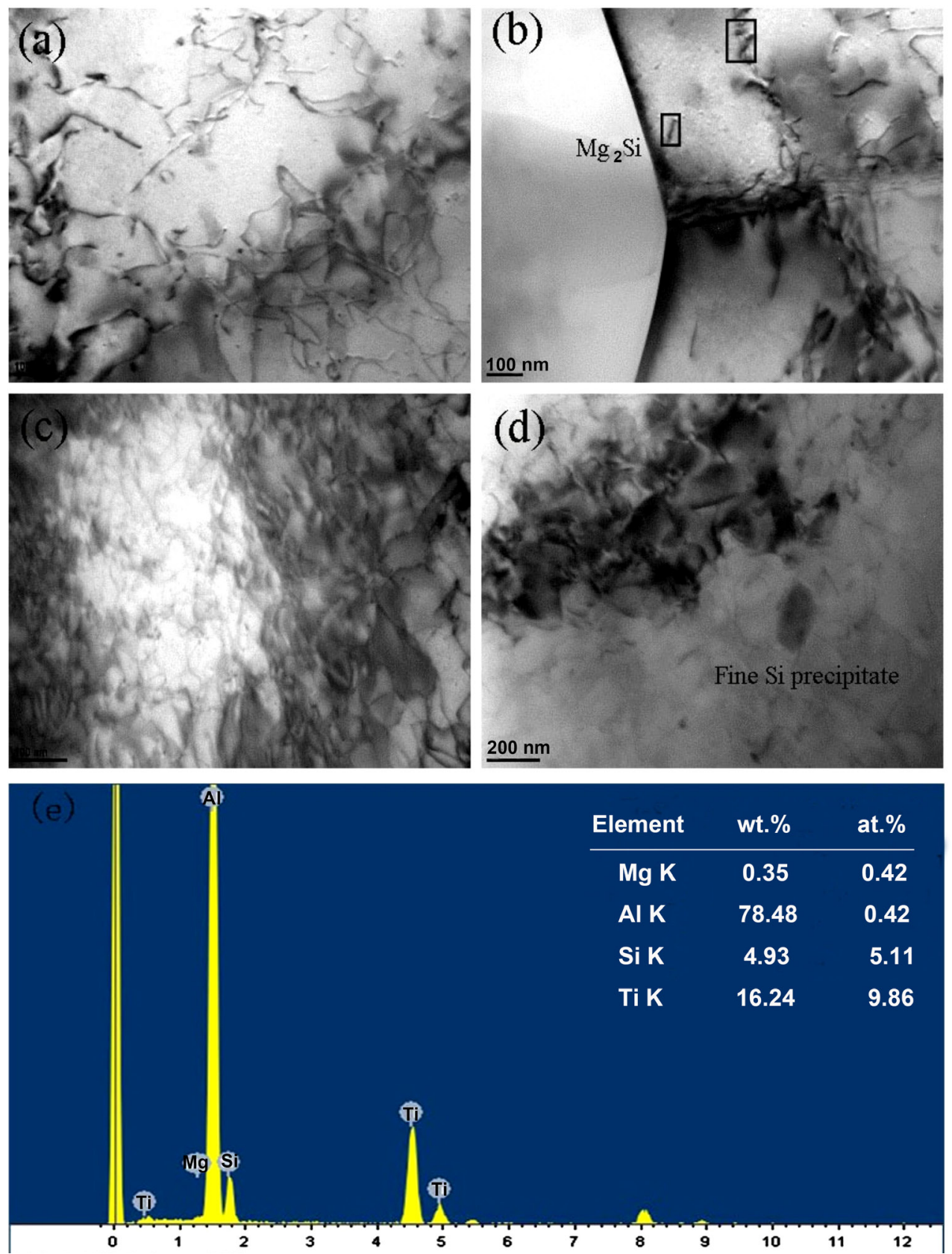

Fig. 8: Typical TEM micrographs to show precipitates and dislocation characteristics of samples: $(a, b) \mathrm{U}$; (c,d) H; (e) EDS analysis of the precipitate in (d)

\subsection{Mechanical properties}

\subsubsection{Micro-hardness evolution}

The results of measured micro-hardness are presented in Fig. 9. It was apparent that the deformed alloys demonstrated decreased micro-hardness compared with the die-cast alloy. Meanwhile, the mean hardness presented different variation trends in different regions comparing these two deformed samples. The specific reasons will be presented later in the discussion part.

\subsubsection{Tensile properties}

The ultimate tensile strength and elongation of alloys are summarized in Table 4. After the hot spinning process, both the strength and ductility were improved. It is worth noting that the elongation of deformed alloy had greatly increased, from $2.85 \%$ (U) to $15 \%(\mathrm{~L})$ and $17.5 \%(\mathrm{H})$, respectively. The quality index of

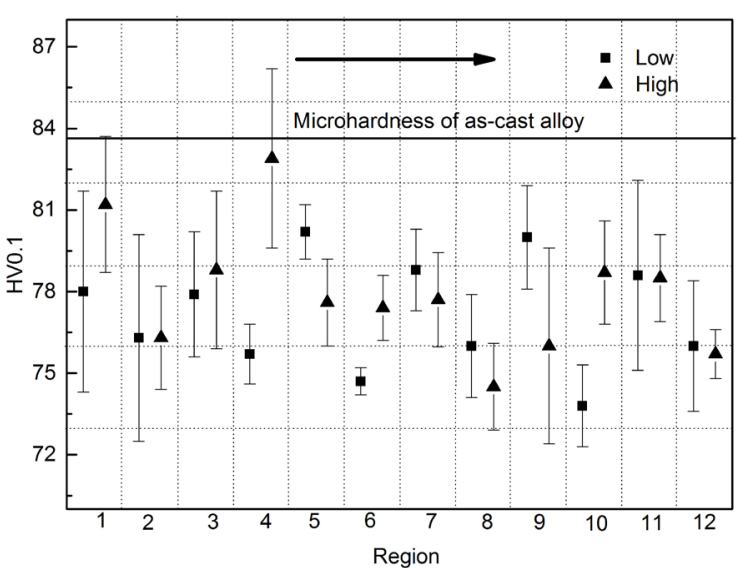

Fig. 9: Comparative micro-hardness of samples (higher solid line denotes micro-hardness of die-cast sample) 
Table 4: Mechanical properties of A356 alloy with different deformations

\begin{tabular}{cccc} 
Sample & UTS(MPa) & El (\%) & Quality index \\
\hline U & 214.29 & 2.85 & 282.52 \\
L & 229.54 & 15.19 & 406.77 \\
H & 236.07 & 17.63 & 423 \\
\hline
\end{tabular}

deformed alloys also improved to about double the die-cast alloy.

\section{Discussion}

\subsection{Microstructural evolution during hot spinning process}

A356 alloy was processed through the hot spinning process in this study. The results in Figs. 3-8 demonstrated that significant changes in microstructure were observed in the deformed alloy compared with the die-cast alloy.

Due to different elastic constant and deformation behavior between the $\alpha-\mathrm{Al}$ matrix and eutectic Si particles, severe plastic deformation results in significant mechanical straining at the interface ${ }^{[21,22]}$. Therefore, eutectic Si particles and Fe-rich phases undergo fragmentation. Meanwhile, the strain induced diffusion accelerates the kinetics of spheroidization, which results in the spheroidization of eutectic Si particles.

Particles stimulating the nucleation mechanism can describe the recrystallization scheme. The hot spinning process produces a high density of dislocations which are high stored energy zones around coarse eutectic Si particles. These energy zones with high stored energy supply preferred recrystallization nucleation sites and hence recrystallization occures ${ }^{[23-25]}$.
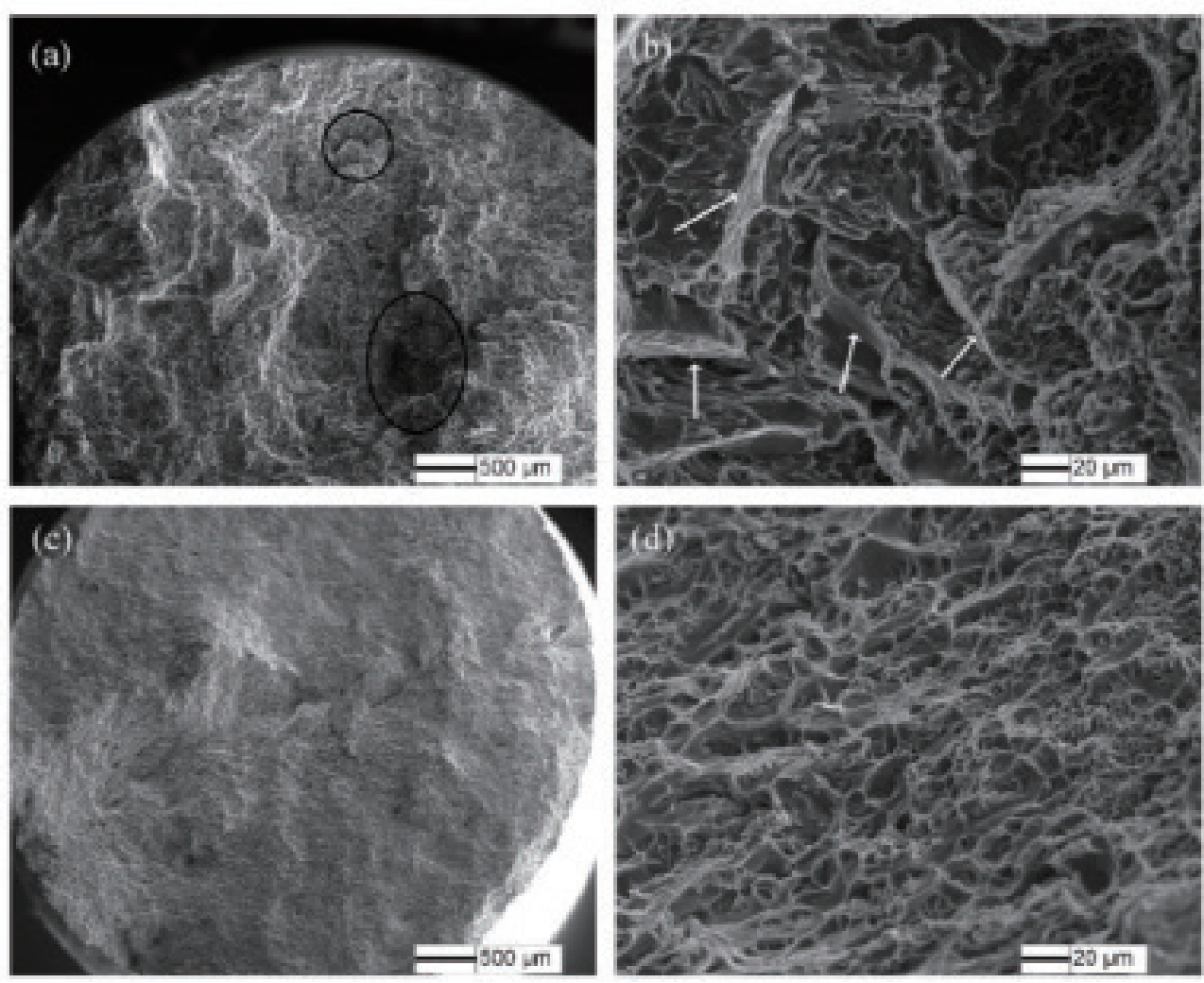

Fig. 10: SEM fractographs obtained from: $(a, b) U$ and (c,d) H deformation

\subsection{Fractography}

It can be seen from the fracture morphologies (Fig.10) that all the fractographs presented a mixed quasi-cleavage-type and dimpletype morphology. Large amounts of porosities marked with circles in Fig. 10(a) could be observed on the fracture surfaces of the die-cast alloy. The fracture path preferentially went through these casting defects, resulting in poorer mechanical properties, especially the poor ductility. Thereafter, a quasi-cleavage feature was clearly observed [Fig. 10(b)]. In contrast, the fractograph of the deformed alloy exhibited an obvious dimple-type fracture morphology with deep and uniform distributed dimples as shown in Figs. 10(c)-(d) and no porosity was seen anymore. This means that the fracture characteristic of samples transformed from a mixed quasi-cleavage-type and dimple-type morphology to dimple-type morphology after the hot spinning process. This is in accordance with the better tensile properties of the deformed alloy, especially the ductility.

\subsection{Changes of mechanical properties after hot spinning process}

The present experiments demonstrated that the hot spinning process improved greatly the ductility of the A356 alloy. However, the variation of strength and hardness was less obvious. Mechanical properties of the A356 alloy largely depend on the size and morphology of the $\alpha-\mathrm{Al}$ matrix and eutectic silicon characteristics ${ }^{[2,3,6,17,26-29]}$. All these structures are influenced by the hot spinning process.

Hardness is a property which is defined as resistance to local plastic deformation. It is widely known that in the Al-7Si alloy, eutectic Si particle is the predominant factor in resisting the local plastic deformation. Therefore, the decrement of average micro-hardness in the deformed alloy is related to the refinement of the eutectic silicon phase caused by plastic strain. The particle-like eutectic Si particles distributing throughout the $\alpha$-Al provide less resistance to plastic deformation compared with the coral-like eutectic Si particles, thus lower hardness is obtained in the deformed alloy. Due to the partial inhomogeneous microstructure in the deformed alloys, the mean microhardness presented different variation trend at different regions.

As stated in 3.2, the elimination of porosities is the main factor for the improvement of ductility. The fragment of Fe-rich phases 
weakened the harmful action of the coarse acicular iron bearing compound on the Al matrix. The finer grains in the deformed alloy had the grain refinement strengthening effect. Meanwhile, a large amount of dislocations were formed through deformation during the hot spinning process. During the tension process, solute atoms and second precipitates particles in the alloy will hinder the movement of dislocations. Meanwhile, this large amount of dislocations will tangle each other. Large force is required to finish the motion of the dislocations. The higher the density of the dislocation, the higher the resistance of the dislocation motion, and the higher the strength. All these comprehensive effects result in the improvement of mechanical properties.

\section{Conclusions}

(1) The microstructural changes validated that the hot spinning process could improve the homogeneity of the microstructure.

(2) Fragment of Si particles and Fe-rich phases occurred during the hot spinning process. Meanwhile, porosities and shrinkages were eliminated.

(3) Finer grain structure and a large amount of dislocations were formed through deformation during the hot spinning process.

(4) A good combination of tensile strength ( 260 MPa) and elongation $(>15 \%)$ was obtained. The improvement of the ductility and ultimate tensile strength was attributed to the elimination of porosities, a high density of dislocations, fractured short-rod like Fe-rich phase, and spheroidization of the Si phase produced by the hot spinning process.

(5) The decrement of microhardness was related to the spheroidization of these eutectic Si particles.

\section{References}

[1] Fakhraei O, and Emamy M. Effects of $\mathrm{Zr}$ and $\mathrm{B}$ on the structure and tensile properties of Al-20\%Mg alloy. Materials \& Design, 2014, 56: 557-564.

[2] Kim HY, Han S W, and Lee H M. The influence of Mn and $\mathrm{Cr}$ on the tensile properties of A356-0.20Fe alloy. Materials Letters, 2006, 60(15): 18801883.

[3] Kim H Y, Park TY, Han S W, et al. Effects of Mn on the crystal structure of a-Al(Mn,Fe)Si particles in A356 alloys. Journal of Crystal Growth, 2006, 21(1): 207-211.

[4] Liu Qing, Zhang Hu, Cui Yuexiang, et al. TEM study of crystal defects of the silicon phase in Al-Si eutectics. Scripta Metallurgica Et Materialia, 1991, 25(2): 371-376.

[5] Liu Qing, Zhang Hu, and Li Qingchun. Orientation relationship between the aluminium and silicon phases in an unmodified Al-Si eutectic. Scripta Metallurgica Et Materialia, 1990, 24(10): 1975-1978.

[6] Razaghian A, Emamy M, Najimi AA, et al. Sr effect on the microstructure and tensile properties of $\mathrm{A} 357$ aluminum alloy and $\mathrm{Al}_{2} \mathrm{O}_{3} / \mathrm{SiC}-\mathrm{A} 357$ cast composites. Materials Characterization, 2009, 60(11): 1361-1369.

[7] Zhang Huarui, Liu Zhenbang, Li Zizhuo, et al. Cooling Rate Sensitivity of RE-Containing Grain Refiner and Its Impact on the Microstructure and Mechanical Properties of A356 Alloy. Acta Metallurgica Sinica (English Letters), 2016, 29(5): 414-421.

[8] Avalle M, Belingardi G, Cavatorta M P, et al. Casting defects and fatigue strength of a die cast aluminium alloy: a comparison between standard specimens and production components. International Journal of Fatigue, 2002, 24(1): 1-9.
[9] Khamei A A and Dehghani K. Hot Ductility of Severe Plastic Deformed AA6061 Aluminum Alloy. Acta Metallurgica Sinica, 2015, 28(3): 322-330.

[10] Mallapur D G, Udupa K R, and Kori S A. Studies on the influence of grain refining and modification on microstructure and mechanical properties of forged A356 alloy. Materials Science and Engineering: A, 2011, 528: 47474752.

[11] Roy M J and Maijer D M. Analysis and modelling of a rotary forming process for cast aluminium alloy A356. Journal of Materials Processing Technology, 2015, 226: 188-204

[12] Cheng Yinchun, Lin Chihkuang, Tan Anhung, et al. Effect of Spinning Deformation Processing on the Wear and Corrosion Properties of Al-7Si0.3Mg Alloys. Materials \& Manufacturing Processes, 2010, 25(7): 689-695.

[13] Cheng Yinchun, Lin Chihkuang, Tan Anhung, et al. Effect of the Spinning Deformation Processing on Mechanical Properties of Al-7Si-0.3Mg Alloys. Journal of Materials Engineering and Performance, 2012, 21(9): 18731878.

[14] Mori K I, Ishiguro M and Isomura Y. Hot shear spinning of cast aluminium alloy parts. Journal of Materials Processing Technology, 2009, 209(7): 3621-3627.

[15] Roy M J and Maijer D M. Response of A356 to warm rotary forming and subsequent T6 heat treatment. Materials Science and Engineering: A, 2014, 611: 223-233.

[16] Zhao Weimin, Jia Xiaofei, Wang Zhifeng, et al. Effects of Spinning on Microstructure and Mechanical Properties of A356 Alloy. Advanced Materials Research, 2011, 189-193: 4014-4017.

[17] Ceschini L, Morri A, Gamberini A, et al. Correlation between ultimate tensile strength and solidification microstructure for the sand cast A357 aluminium alloy. Materials \& Design, 2009, 30(10): 4525-4531.

[18] Shaha S K, Czenwinski F, Kasprzak W, et al. Microstructure and mechanical properties of Al-Si cast alloy with additions of Zr-V-Ti. Materials \& Design, 2015, 83: 801-812.

[19] Wu Yuna, Liao Hengcheng, Liu Yabing, et al. Dynamic precipitation of $\mathrm{Mg}_{2} \mathrm{Si}$ induced by temperature and strain during hot extrusion and its impact on microstructure and mechanical properties of near eutectic Al-Si-Mg-V alloy. Materials Science and Engineering: A, 2014, 614: 162-170.

[20] Wang Yongjin, Liao Hengcheng, Wu Yuna, et al. Effect of Si content on microstructure and mechanical properties of Al-Si-Mg alloys. Materials \& Design, 2014, 53(1): 634-638.

[21] Mueller M G, Fornabaio M, Zagar G, et al. Microscopic strength of silicon particles in an aluminium-silicon alloy. Acta Materialia, 2016, 105: 165-175.

[22] Patakham $U$ and Limmaneevichitr $C$. Effects of iron on intermetallic compound formation in scandium modified Al-Si-Mg Alloys. Journal of Alloys and Compounds, 2014, 616: 198-207.

[23] Gutierrez-Urrutia I, Munoz-Moriis M A. Contribution of microstructural parameters to strengthening in an ultrafine-grained $\mathrm{Al}-7 \% \mathrm{Si}$ alloy processed by severe deformation. Acta Materialia, 2007, 55(4): 1319-1330.

[24] Gutierrez-Urrutia I, Munoz-Moriis M A, Puertas I, et al. Influence of processing temperature and die angle on the grain microstructure produced by severe deformation of an $\mathrm{Al}-7 \%$ Si alloy. Materials Science \& Engineering A, 2008, 475: 268-278.

[25] Ding Ke, Liao Hengcheng, Jin Qiumin, et al. Effect of hot extrusion on mechanical properties and microstructure of near eutectic Al-12.0\%Si$0.2 \% \mathrm{Mg}$ alloy. Materials Science and Engineering: A, 2010, 527(26): 68876892.

[26] Birol Y. Response to artificial ageing of dendritic and globular Al-7Si-Mg alloys. Journal of Alloys and Compounds, 2009, 484: 164-167.

[27] Dispinar D and Campbell J. Effect of casting conditions on aluminium metal quality. Journal of Materials Processing Technology, 2007, 182: 405-410.

[28] Wu Yuna, Liao Hengcheng, and Zhou Kexin. Effect of minor addition of vanadium on mechanical properties and microstructures of as-extruded near eutectic Al-Si-Mg alloy. Materials Science and Engineering: A, 2014, 602: 41-48.

[29] Yu Janbo, Ren Zhongming, Ren Weili, et al. Solidification structure of eutectic Al-Si alloy under a high magnetic field-and-electromagnetic vibration. Acta Metallurgica Sinica, 2009, 22(3): 191-196. 